\title{
DOES PRINCIPAL'S MINDSET HAVE CORRELATION WITH SCHOOL'S WORK CULTURE?
}

\author{
Muflih Ma'mun ${ }^{a *}$, Dedy Achmad Kurniady ${ }^{\text {b }}$ \\ ${ }^{a^{*}}$ Prodi PIAUD STAI Darul Falah Bandung Barat \\ Jl. Raya Cihampelas No. 96, Bandung Barat, Jawa Barat, Indonesia, ganungadpend@gmail.com \\ ${ }^{\mathrm{b}}$ Prodi Administrasi Pendidikan Universitas Pendidikan Indonesia \\ Jl. Dr. Setiabudhi No. 2Dr. Setiabudi No.229, Isola, Kota Bandung, Jawa Barat, Indonesia, dedy_achmad@upi.edu
}

\begin{abstract}
The success of school principals in changing the work culture of a better school depends on the mindset of change they have. This study seeks to prove whether or not there is an influence on the principal's mindset of leadership on work culture in schools. The research was conducted on 156 state Junior High School's teachers in West Bandung Regency, West Java. Through survey methods and quantitative approaches, the data obtained were analyzed using correlation technique analysis. The results showed that the principal's mindset had a significant correlation with school's work culture. This is based on Pearson's correlation value of 0.510 , and included in the strong correlation category. As a recommendation, school principals must have a transformative, innovative and visionary principal's mindset in building a work culture in schools.
\end{abstract}

Keywords: principal's mindset, school's work culture

Received: 23 June 2018 - Revised: 15 Sep 2019 - Accepted 12 Nov 2019 - Available online 30 Dec 2019

\section{INTRODUCTION}

The realization of work culture in schools can be actualized in various forms such as; academic culture, discipline culture, work culture, clean school culture, and other forms. The diversity of cultural forms is a reflection of a holistic and harmonious school in the delivery of education. Specifically with regard to the effectiveness and productivity of schools, the study point of view of school culture is embedded in the work culture of school members, especially teachers, considering that most of the school activities involve teachers as the spearhead of the successful implementation of education in schools.

In the literature review, the concept of teacher's work culture basically refers to the concept of organizational culture that has a shared meaning shared by each member of the organization. There are five main elements in work culture, namely: science, beliefs, art, morals, law, customs, behavior or habits, norms of society, basic assumptions, value systems, learning or inheritance, and problems of external adaptation and internal integration.

The existence of a work culture of teachers in schools is expected to increase the effectiveness and academic productivity and school performance, be able to build trust in all school members, especially teachers to be able to achieve productivity in work, encourage sustainable innovation, and encourage the establishment of a safe and orderly learning environment for teacher. Work culture must be seen as an inseparable system of all activities inherent in the members of the organization in the implementation of the roles and functions carried out by each member of the organization. 
The existence of work culture in schools is also one indication of the existence of effective schools which, according to Edmonds (1976) are characterized by: (a) the existence of teachers having strong leadership and the principal giving high attention to improving teaching quality; (b) the existence of teachers has high expectation conditions to support student achievement; (c) a school atmosphere that is not rigid, cool without pressure and is conducive to the entire teaching process or a comfortable climate setting; (d) the school has a broad understanding of the focus of teaching and striving for the effectiveness of schools with energy and school resources to achieve teaching objectives to the full; and (e) schools are effective in ensuring the progress of students who are monitored periodically. therefore, in order for the teacher's work culture to materialize, commitment from the school principal, consistency of school work programs and the seriousness of the principal as a guide and support for school members in carrying out their respective roles and functions.

The reality that occurs in several junior high schools in West Bandung Regency shows conditions that are different from what is expected. The observations made indicate a decline in the culture of teacher performance in the past five years. Teacher work culture that is developing at this time does not reflect productive work culture of teachers including: (a) commitment and work discipline that has decreased; (b) cooperation between teachers is not going well; (c) adherence to school rules that have not been fully implemented, and (d) the lack of desire of the teacher to progress and develop in work is an indication of a decline in teacher work culture. One of the factors causing this condition is the lack of clarity in the program and the direction of school. This condition occurs because the school's principal's mindset is less transformative, innovative, and visionary in developing and developing work culture in schools.

The principal's mindset owned by the principal is the most important capital in running, renewing, developing, and changing the work culture of teachers in schools. Thus, the principal has many strategies that can lead to the development and change of a teacher's work culture for the better.

Principals with a good principal's mindset have the ability to rationalize future hopes and ideals in the form of measurable practical activities that can be carried out by all school members. He has deeply understood what every school member wants and makes it a valuable asset. $\mathrm{He}$ is also directly involved and attached to every activity carried out by the teacher in his responsibilities as a guide; listening to teacher complaints and desires, engaging and actively participating with the teacher; as well as having the flexibility to accept criticism or input, and suggestions for improvements given to him; together with the teacher thinking about the strategic steps to develop the school; and prioritizing the interests of teachers over personal interests. In addition, the main priority for school principals with a good principal's mindset is how to achieve school goals effectively and efficiently through efforts to empower school resources based on school values and cultureintention.

Principals as leaders in schools have a strategic role in efforts to shape and build a productive work culture of teachers that can improve school performance. The school principal is an element of the school who has formal authority and authority to encourage, instruct, and if necessary force teachers with the authority to align the jobs for which they are responsible according to the established school values, norms, beliefs and rules.

The effectiveness of the principal's leadership based on the mindset provides encouragement and direction to its members can be raised in the form of discipline at the highest level, namely self-awareness of the rules of the game in the organization.

Strategic decisions made by school principals to bring about better change must be based on careful consideration and reasoning; emphasize the objectivity of clarity in thinking rationally, consider the conditions that occur in the environment responsively, and then align with the vision and mission of the changes to be made. Not only that, the results 
of the determined decision must also be communicated to all school members, especially teachers through a comprehensive approach so that mutual understanding can be realized.

In other words, school principals in order to be able to encourage changes in the culture of productive teacher performance, need a principal's mindset and take a good communication approach to teachers at school. Thus, opportunities for schools in realizing a productive teacher performance culture are increasingly open.

\section{School's Work Culture}

Work culture is a system of mutual orientation that appears to unite the unit and give it a special identity. However, there are major disagreements about what is shared or shared with norms, values, philosophies, perspectives, beliefs, expectations, attitudes, myths, or ceremonies (Wayne K. Hoy and Cecil G Miskel: 2014: 270). The concept of true work culture is derived from the concept of organizational culture (organization culture). Edgar H. Schein (1992: 16) in his work "Organizational Culture and Leadership" which is widely used as a reference for writing about organizational culture, defines more broadly that culture is a pattern of share basic assumption that the group learner as it solved its problems of external adaptation and internal integration, that has worked well enough to be considered valid and therefore, to be taught to new members as the correct way to perceive, think and feel in relation to these problems.

School's work culture is an attempt to realize the conditions felt by individuals who emerge from the feelings, impressions, atmosphere, character that is shown in the form of work carried out as an effort to carry out roles and responsibilities in the organization. School's work culture refers to an organizational culture system that has a shared meaning shared by its members to differentiate the organization from other organizations. Schein explained the cultural elements, namely: science, beliefs, art, morals, law, customs, behavior or habits, norms of society, basic assumptions, value systems, learning or inheritance, and problems of external adaptation and internal integration.

Furthermore Schein (2002) states that culture consists of three layers or levels:

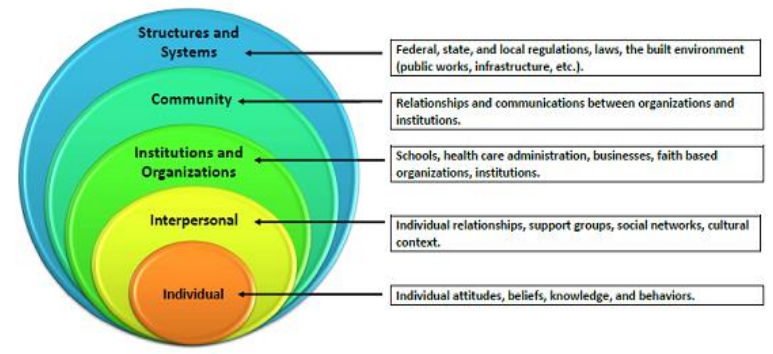

Figure 1. Level of School's Work Culture (CDC, 2013)

(1) artefacts: where the activities or forms of the organization look like organizational structures and processes, the physical environment of the organization and the products it produces. (2) espoused values: are supported values, consisting of strategy, goals, and organizational philosophy. This level has significance in leadership, these values must be instilled in each member of the organization. (3) underlying assumption: is a belief that is considered to have to exist in each member about the organization which includes aspects of beliefs, thoughts and feelings of attachment to the organization.

School work culture has cultural levels manifested in the form of school norms, shared values, and basic assumptions, each of which takes place at different levels of inwardness and abstraction. At the development level, work culture is built and grows from the personal scope of individuals, then moves toward interpersonal, institutional and organizational, community, and the highest level of work culture is within the scope of organizational structure and systems.

Figure 1. Level of School's Work Culture (CDC, 2013)

In work culture, school norms are usually in the form of unwritten expectations and information that appears just below the surface of diving. School norms affect the behavior of teachers and students directly. Norms are far more visible than basic values 
or assumptions, as a consequence, they provide clear tools to help people understand the cultural aspects of organizational life.

The value that schools have is a belief in something to be achieved in education. Values are a reflection of basic cultural assumptions, and are at the next level of analysis. Values often determine what members should do to be successful in the organization.

Firestone \& Wilson (1985) provide a useful conceptual framework for starting to study the organizational culture of schools. Both states that an analysis of school culture can be done by studying the contents, cultural expressions, and main communication patterns. Symbols that become a means of expressing culture often help and identify important cultural themes. Three symbol systems communicate the contents of school culture: cheerful, iconic, and ritual. Stories are narratives that are based on real events, but stories often combine truth with fiction. Icons are physical artifacts used to convey culture or culture (logos, mottos and trophies). Rituals are ceremonies and routine activities that show something important in the organization.

\section{Leader's Mindset}

The notion of mindset can also be understood through the paradigm of a leader in running an organization. Mindset is an established mental attitude that is formed through education, experience and prejudice ". From this definition it can be concluded that the mindset can be formed intentionally (through education and experience designed through the system) or left to form by itself-through experience that was not designed and through prejudice (Mulyadi, 2007:71).

Carol S. Dweck (2008) mentions the mindset consists of three main components, there are paradigm, basic beliefs, and basic values. Paradigm is a method used by someone in seeing something. Denzin \& Lincoln (1994:105) defines the paradigm as a basic belief system or worldview that guides the investigator, not only in choices of methods but in ontologically and epistemologically fundamental ways, which guides researchers not only in choosing methods but also fundamental methods that are ontological and epistemological.

In brief, Denzin \& Lincoln (1994:107) defines the paradigm as basic belief systems based on ontological, epistemological, and methodological assumptions. The paradigm is a basic belief system based on ontological, epistemological, and methodological assumptions.

The second element of the mindset is basic beliefs. Basic beliefs are beliefs that are attached by someone to something. If we do something we believe in, we will do it wholeheartedly. Confidence is an attitude that is shown by humans when they feel they know enough and conclude that they have reached the truth. Because belief is an attitude, one's belief is not always true or, belief alone is not a guarantee of truth. if there is no belief, doubts will arise, and mistakes will often get in the way. beliefs are very important in life as beliefs in religion (Nopva: 2011).

Trusting belief is the extent to which a person believes and feels confident of others in a situation. Trusting belief is the perception of the party that believes (consumers) to the party that is trusted in which the seller has characteristics that will benefit consumers. McKnight et al (2002:21) states that there are three elements that build trusting beliefs, namely benevolence, integrity, competence.

The next element of the mindset is the basic value. Basic values are attitudes, traits, and characters that are upheld by someone, so based on these values a person is restricted. Value or value is a belief or belief that is applied in the form of behavior by individuals in everyday life. There are ten types of values called a motivational type of value according to Schwartz (2010: 5), there are: (a) power; (b) achievement, (c) hedonism; (d) stimulation, (e) self-direction, universalism, (g) traditional, (h) conformity, and (i) security.

Principals' mindset as the spearhead of achieving the school goals is very necessary in the development, renewal, improvement and change in school culture, in this case the principal must be able to have a very good mindset in developing strategies to be able to know and unite all aspects of behavior from 
school residents who are included in the school work culture.

Principals' mindset can be defined as the principal's efforts to influence all activities that occur in the culture of the school, where the principal makes a thought towards renewal, improvement, development or change in a better work culture. In addition, the principal's mindset also focuses on creating a direct organizational climate with participatory action and the development or change of work culture through effective communication.

Stogdill (1981) argues that leaders must have the trait which has the drive for responsibility, task completion, persistence in achieving goals, encouragement to train initiatives in social situations, the ability to create innovation to achieve goals, the ability to influence the behavior of others, and the ability to adapt the system of interactions to the objectives at hand.

Carol Dweck (2006) states that there are two kinds in the mindset of a leader, in which the two forms of mindset are divided into fixed mindset and growth mindset. Fixed mindset is a mindset that cannot be improved. This type of mindset is a negative mindset, pessimistic, insecure, satisfied with the present situation, and so on. People who hold these beliefs think that "they are their way", but that does not mean that they have less of a desire for a positive self-image than others.

Fixed mindset attached to individuals who believe in the basic qualities that exist in themselves and do not need to be developed again. Like intelligence or possessed talent that is realistically fixed. Individuals included in the fixed mindset spend time not developing their intelligence or talents. $\mathrm{He}$ also believes that talent alone is enough to create success. Individual criteria included in the fixed mindset according to Dweck (2009), are: (a) want to look smart, (b) avoid challenges, (c) ignore useful negative feedback, (d) feel threatened by the success of others, (e) early plateau and achieve less than their full potential.

Growth mindset is an individual's view that intelligence and talent can be developed through practice, training, methods that are positive, optimistic, always wanting to try, keep on fighting, believe that can be more advanced, and so on. Individuals belonging to the growth mindset believe that their most basic abilities can be developed through dedication and hard-brain work and talent is only seen as basic capital.

This view has an impact on the psychological condition of the individual in the form of a willingness to change, want to continue to learn, and the ability or self-endurance is very good in their efforts to achieve better performance. Individuals with growth mindset characteristics are as follows: (a) want to learn, (b) embrace challenges, (c) learn from criticism, (d) find lessons and inspiration in the success of others, and (e) reach everhigher level of achievement..

\section{METHODS}

Table 1. The Result of Pearson Correlation

\begin{tabular}{cccr}
\hline & & $\begin{array}{c}\text { Principal's } \\
\text { Mindset }\end{array}$ & \multicolumn{2}{c}{$\begin{array}{c}\text { School's } \\
\text { Work Culture }\end{array}$} \\
\hline Principal's & $\begin{array}{c}\text { Pearson } \\
\text { Correlation }\end{array}$ & 1 & $.510^{* *}$ \\
Mindset & Sig. (2-tailed) & & .000 \\
& $\mathrm{~N}$ & 156 & 156 \\
\hline$* *$ Correlation is significant at the 0.01 level (2-tailed).
\end{tabular}

This research was conducted at public and private junior high schools in West Bandung Regency, West Java Province. Researchers used survey methods and quantitative approaches. As for determining the number of samples, researchers used stratified random sampling techniques and obtained a sample of 156 teachers. Data were collected using a questionnaire and analysis using correlation technique analysis.

Statistic analysis. Calculation of the correlation value in this study uses the Pearson's Correlation product moment technique, using IBM SPSS 23. The results of these calculations are explained in the table 1 .

Based on the calculation above, the correlation value obtained for the principal's mindset with the school's work culture is 0.510 , which means there is a relationship between the principal's mindset and the school's work culture. As for the relationship between the principal's mindset and the 
school's work culture, the value of 0.000 , which means that the relationship of these variables is significant. Then it can be concluded that the principal's mindset has a significant relationship with the school's work culture in junior high schools in West Bandung Regency, West Java, both in public or private schools

\section{RESULTS AND DISCUSSION}

The results showed a significant and positive correlation between the variables of the principal's mindset with the school's work culture.

Mindset is a person's position or mental outlook that influences the person's approach in dealing with a phenomenon. Mindset consists of a set of assumptions, methods, or records that are owned by a person or group that is very strongly embedded. Every individual has a mindset and way of looking at something; events, phenomena, facts, certain events that cage differ from one individual to another. This difference can be caused by differences in experience, level of education, intelligence, and ability in adjusting the conditions to the orientation described by the individual.

Leader's mindset is a concept that bases on the paradigm, beliefs, and values that exist in the leader of the reality that occurs in schools whether it involves physical resources such as the environment or personal conditions that exist as a unitary system that has a strategic role in efforts to achieve school goals. The principal with his mindset as a leader views that every element in the school has a reciprocal relationship and influences one another as a system.

Schools as an open system that will certainly be influenced by various things that are outside their environment. Even the school input itself comes from the community and will return to the community (Hoy \& Miskel, 2001). This further reinforces that the principal as a school leader must respond positively to the various changes that occur. So the principal with his role as a leader must have self-sensitivity to the conditions that occur in the environment and have a proper perspective of how this can lead to better change.

Correlation of principal's mindset with school work culture that the principal is the first party to spearhead the emergence and development of work culture in schools through the leadership mechanism he plays. Principals with a transformational and visionary mindset allow for a more effective change in teacher work culture. The influence of leadership on change is stated by Hersey (2000: 491) that influential leaders do not implement changes in vacuum conditions, but that change is carefully perfected through the creation of various sections. Furthermore Hersey (2000) explains that by considering and looking at the factors that influence the success of the change, positive impacts can be proposed for the change to occur. This is caused by leadership occurring within the scope of social processes.

The principal's mindset is as a school guide in the effort to develop and prepare physical and environmental conditions that can help teachers actualize personal and work values and show them in the form of achievement. What kind of policies and programs the principal wishes to realize is actually a form of rationalization of the mindset that is owned? In its stages, this form of rationalization can start from: (1) an understanding of which aspects or elements must be improved in the teacher and the position or the extent to which the teacher will be developed, (2) the condition of the school; strengths, weaknesses, external opportunities that can be utilized, (3) the rationality of activities that can be carried out and can be achieved, (4) predictions of factors that hinder the achievement, and (5) the effectiveness of activities and improvement efforts that can be done.

Leadership occurs through social processes in the form of influence on others to behave and act as expected. This was confirmed by Chemers (1997:1) who stated that leadership is a process of social influence when a person is able to stimulate the help and support of others in order to realize together. Leadership involves a process of social influence when an 
individual exerts deliberate influence on others to arrange activities and relationships within a group or organization.

The concept of work culture which is a derivative of organizational culture implies the dominant values that are owned by individuals and is supported by institutions to guide individuals to behave and respond to all elements of the institution including stakeholders. In the scope of schools, this form is actualized in the form of implementation of work in schools and the basic assumptions or beliefs held by school personnel.

School's work culture refers to a system of values, beliefs and norms that are mutually accepted, and implemented with full awareness as a natural behavior, formed by an environment that creates a common understanding among all elements and personnel of the school whether principals, teachers, staff, students and if necessary form the same community opinion as the school. School's work culture refers to an organizational culture system that has a shared meaning shared by its members to differentiate the organization from other organizations. If the school culture emphasizes a greater scope, namely the school and its elements and systems, while the work culture emphasizes the psychological aspects and the role of individuals in the form of work that must be carried out as part of the school (personal values and actual performance).

Principals through a transformative, inviting, and visionary mindset building work culture in schools can be done by making effective personal or group communication by sitting with teachers and staff talking about hopes and desires to be realized, needs to be met to support fluency in work, complaints and obstacles encountered and immediately to be resolved, as well as building a shared commitment for the progress of the school.

Communication becomes a strategic element for a leader in managing and directing people through the process of directing, persuasion, and instructions to do something. Because without communication, togetherness cannot be established, understanding cannot be achieved, and conflict will arise as a result of mistakes in interpreting intentions or desires.

The second way that principals can use in implementing transformative, innovative, and visionary ideas is to improve the mental quality and cognitive activities of teachers and staff in looking at the reality of the school environment that occurs. School as a social system moves dynamically to follow changes in the environment due to the dynamics of the needs and desires of the community towards education. If this is the case, something that is decided by the school principal as a form of accommodation to ensure that the school can survive or continue to survive is something that is absolutely necessary.

This is where the importance of the principal has a relevant mindset in leading a culture of work change. Where will the school be taken in the future? What efforts can be made to accommodate ongoing changes? What positions and conditions does the school want to achieve now and then? The question is an attempt to find a formula for handling uncertain conditions and must be faced by schools. Mindset is an established mental attitude that is formed through education, experience and prejudice.

Both ways are basically intended to improve the quality of work culture in schools. This is because work culture has a significant influence on improving the quality or quality of schools.

Referring to the explanation above, the principal's mindset in relation to work culture in school then focuses on the scope of:

(1) the development and dissemination of the vision of the institution-shared vision;

(2) the application of effective communication;

(3) becoming a pioneer in changing work culture-change agent;

(4) positioning themselves as trainers, mentors, and assistants, and

(5) efforts to utilize all resources to achieve common goals 
Muflih Ma'mun, et al. / Journal of Educational Administration Research and Review/Vol. 2 No. 2

December 2018

\section{CONCLUSION/RECOMENDATION}

The results showed a significant correlation and included in the strong category between principal's mindset and school's work culture. The strength of the relationship is due to the internal aspects of the principal, such as experience, maturity, knowledge and insight, education, training that is followed, the willingness to learn and develop, and the desire to progress and show the best achievements.

As a recommendation from this study, the principal should try to create a conducive school culture, so that teachers, students and school staff have the freedom to develop and increase their potential. These efforts can be done by organizing training in schools, inhouse training, teacher gathering, open houses, persuasive approaches through interpersonal communication, the provision of supporting work infrastructure, and in the form of policies such as the awarding and compensation.

\section{REFERENCES}

Clive Dimmock and Allan Walker. 2005. Educational Leadership: Culture and Diversity. SAGE Publications: London

Departement of education State of Delaware.(2001). Building Successful School Leaders in Times of Great Change; Delaware School leadership Task Force : Report and Recommendation. U.S. : Institute for Public Administration
Esther Cameron and Mike Green. 2012. A complete guide to the models, tools and techniques of organizational change. Kogan Page Limited : United States

Europian Comission. (2000). European Report on The Quality of School Education: Sixteen Quality Indicators; Report Based on The Work of The Working Committee on Quality Indicators. Luxemburg: European Commission DirectorateGeneral for Education and Culture.

Hoy and Miskel. (2001). Educational Administration; Theory, Research, and Practice Sixth Edition. New York : McGrawhill.

Institute of Educational Leadership.(2000). Leadership for Student Learning: Reinventing the Principalship; A School Leadership for 21st Century Initiative A Report of thr Task Force on Principalship. Washington, D.C.

Institute of Educational Leadership.(2001). Leadership for Student Learning: Restucturing School District Leadership; School

John B. McGuire Gary B. Rhodes. 2009.Transforming Your Leadership Culture. Jossey-Bass: San Francisco

Leadership for 21st Century Initiative A Report of thr Task Force on Principalship. Washington, D.C.

Michael Fullan. 2001. Leading in a culture of

National Association of Secondary School Principals (2001). Prioroties and Barriers in High School Leadership : A Survey of Principals. Virginia : NASSP

Oteng Sutisna. (1985). Administrasi Pendidikan Dasar Teoritis Untuk Praktek Profesional. Bandung: Angkasa

Richards F. Elmore. (2000). Building a New Structure for School Leadership. Washington, D.C.: Albert Shanker Institut 